Article

\title{
Physicochemical Characterization of Santa Barbara Amorphous-15 (SBA-15) and Its Functionalization with Polyaniline for Phenol Adsorption
}

\author{
Lady Johana Cárdenas ${ }^{1}$, Liliana Giraldo ${ }^{1}$ and Juan Carlos Moreno-Piraján ${ }^{2, *} \mathbb{D}$ \\ 1 Grupo de Investigación en Calorimetría, Departamento de Química, Facultad de Ciencias, \\ Universidad Nacional de Colombia, Bogota 111711, Colombia; lacardenas@unal.edu.co (L.J.C.); \\ lgiraldogu@unal.edu.co (L.G.) \\ 2 Grupo de Investigación en Sólidos Porosos y Calorimetría, Departamento de Química, Facultad de Ciencias, \\ Universidad de los Andes, Bogota 111711, Colombia \\ * Correspondence: jumoreno@uniandes.edu.co
}

Citation: Cárdenas, L.J.; Giraldo, L.; Moreno-Piraján, J.C. Physicochemical Characterization of Santa Barbara Amorphous-15 (SBA-15) and Its Functionalization with Polyaniline for Phenol Adsorption. Processes 2022, 10, 188. https://doi.org/10.3390/ pr10020188

Academic Editors: Avelino Núñez-Delgado, Zhien Zhang, Yaoyu Zhou, Marco Race, Elza Bontempi and Mario Coccia

Received: 27 October 2021 Accepted: 11 January 2022 Published: 18 January 2022

Publisher's Note: MDPI stays neutral with regard to jurisdictional claims in published maps and institutional affiliations.

Copyright: (C) 2022 by the authors. Licensee MDPI, Basel, Switzerland. This article is an open access article distributed under the terms and conditions of the Creative Commons Attribution (CC BY) license (https:// creativecommons.org/licenses/by/ $4.0 /)$.

\begin{abstract}
The chemical surface of Santa Barbara Amorphous-15 (SBA-15) was functionalized with polyaniline (SBA-15/PA) and was prepared using aniline and ammonium persulfate as the modifying agent and oxidant. The samples were characterized by $\mathrm{N}_{2}$ physical adsorption at $77 \mathrm{~K}$. SBA-15's surface area was $654.5 \mathrm{~m}^{2} \mathrm{~g}^{-1}$, changing to $254.6 \mathrm{~m}^{2} \mathrm{~g}^{-1}$. The total acidity and basicity were determined using a modified Boehm's method, and the point of zero charge $\mathrm{pH}\left(\mathrm{pH}_{\mathrm{pzc}}\right)$ was determined. Immersion calorimetry in water, benzene, and $\mathrm{NaOH}, \mathrm{HCl}$, and phenol $\left(100 \mathrm{mg} \mathrm{L}^{-1}\right)$ solutions was performed, producing values ranging from -15.1 to $-174.1 \mathrm{~J} \mathrm{~g}^{-1}$ related to the chemical surface, $\mathrm{pH}_{\mathrm{pzc}}$, and acid and base group values. Finally, the phenol adsorption capacity was found to be higher for the modified polyaniline silica, at $138 \mathrm{mg} \mathrm{g}^{-1}$.
\end{abstract}

Keywords: SBA-15; phenol; functionalization; adsorption; immersion calorimetry

\section{Introduction}

According to the Environmental Protection Agency (EPA) [1], phenol is considered a priority pollutant, dangerous for the environment due to its high toxicity even at low concentrations. In Colombia, according to the Ministry of Environment and Sustainable Development in resolution 631 of 2015, the maximum permissible limit for phenol in wastewater discharges is $0.2 \mathrm{mg} \mathrm{L}^{-1}$. The most common sources of phenol in water are effluents from industries that manufacture iron, rubber, resins, plastics, fibers, adhesives, and synthetic fuels. Phenol can be found in air and water because of the use and disposal of products that contain this substance; in the soil it tends to move into groundwater. Phenolcontaminated water sources have a bad taste and odor, so it is necessary to remove it in order to avoid repercussions for human health and the ecosystem [1,2]. According to the World Health Organization (WHO), the treatments to be carried out to produce safe water depend on the quality that is desired; a process to achieve basic levels of sanitation requires up to four barriers to eliminate traces of organic compounds: a typical water treatment scheme includes physical separation, passage through a membrane bioreactor or activated sludge, followed by treatment, such as advanced oxidation, activated carbon adsorption, or membrane filtration $[2,3]$. As mentioned in the first paragraph of this introduction, in Colombia, as in many Latin American countries, phenol is one of the compounds found in aquifer systems, generating major health problems for the entire population, especially the most unprotected, and mainly children. Several methods have been developed for the removal of phenol from water, such as photocatalytic degradation, electrochemical oxidation, solvent extraction, and biological degradation and adsorption, which is one of the most widely used methods for decontamination [4-11]. 
Adsorption on porous adsorbents is an alternative to processes like advanced oxidation, chlorination, and ozonation which involve reactive molecules, such as drugs, which can result in the production of more toxic compounds if agents such as hydrogen peroxide, ozone, and chlorine are present, giving rise to organochlorine compounds, furans, dioxins, and chloroform-molecules that have greater persistence and low degradability in the environment. Activated carbon is considered a non-reactive barrier that retains organic and inorganic compounds due to its physicochemical properties, such as high surface area, porosity, and the presence of surface chemical groups that allow it to interact with compounds that have several chemical characteristics [5-7].

According to scientific studies for Colombia, there is evidence for the presence of several kind of molecules, including those for pharmaceutical use, in water sources, generating a great problem that is concerning for state, environmental, political, and academic organizations in the context of evaluating solutions from different areas. One of the processes endorsed by the $\mathrm{WHO}$ in the guide for the production of safe water is adsorption on porous solids because it is considered an alternative to chemical processes that change the properties of pharmaceutical compounds, turning them into more toxic substances with greater difficulty of removal $[7,10]$.

Colombia has a serious problem in the form of phenol contamination in water, which manifests itself by causing a noticeable unpleasant taste and odor change through the chlorination of water, despite the fact that its concentration is at ppm level and even less than that. Most phenols and their derivates are corrosive to skin and eye. In Colombia, as well as in other countries in the area, coal distillation and organic synthesis waste flows bearing coal entities contain large amounts of phenols and their derivatives, as well as phenolic compounds, which are present in wastewater from pulp and paper-bleaching facilities, and from resin, pesticide, insecticide, paint, and solvent industries. That is why it is very important to face this problem and generate solutions that can be scaled to the most vulnerable populations; it is a social duty for academia [8,9].

The adsorption process of phenolic compounds has been evaluated in several studies. The main conclusions shared by these works are that the adsorption process depends on factors such as the physical nature of the adsorbent (porous structure, surface chemistry), the physical nature of the adsorbate (pKa, polarity, size), and conditions of the solution ( $\mathrm{pH}$, ionic strength, adsorbate concentration) [2-6].

Regarding the adsorbent, factors such as geometric and chemical heterogeneity have been considered from the initial composition of the precursor, which affect the phenol adsorption process due to the presence of pores of different sizes that modify not only the kinetics of the process but also the adsorption capacity, since by increasing the volume of the micropores the amount of phenol adsorbed decreases [4]. On the other hand, the presence of narrow microporosity may not favor the process because phenol can form aggregates with water and increase its size, presenting diffusive restrictions in very small pores, as indicated by the kinetic data reported in the literature [5,7].

The analysis of the influence of surface chemistry on the adsorption capacity of phenol has also been evaluated. Studies conclude that activated carbon surfaces that have been subjected to oxidative treatments have lower adsorption capacities due to an increase in polarity in the surface which raises the affinity for the solvent, generating a blockage of the pores, so that the phenol interacts with the activated carbon through interactions with $\pi$ electrons. However, an excess of oxidized groups can generate an inductive effect of electrons, also weakening the formation of interactions of this type [2,6].

Another of the postulated mechanisms for the adsorption of phenol on other adsorbents, such as activated carbons, is the electron donor-acceptor interaction, where the carbonyl groups of activated carbon are electron donors and the aromatic ring of phenol is the acceptor. Some authors have reported [7] the effect of heat treatment of activated carbons on phenol adsorption. According to the data, the process is favored in an activated carbon subjected to heat treatment at $1173 \mathrm{~K}$, followed by treatment at $973 \mathrm{~K}$, and finally at $1373 \mathrm{~K}$. The author attributes this behavior to the increase in surface area caused by 
the increase in porous structures generated in the heat treatment; however, an excess of temperature leads to the collapse of the porous structure. When comparing the adsorption capacities of activated carbon without heat treatment and with treatment at $1173 \mathrm{~K}$ for different temperatures for the adsorption system $(298 \mathrm{~K}, 313 \mathrm{~K}, 328 \mathrm{~K})$, it was found that the adsorption capacity does not vary with temperature but the heat treatment for the sample favors the process $\left(1.27<1.54 \mathrm{mmol} \mathrm{g}^{-1}\right)$ [7-11].

On the other hand, other authors have reported [8] that the isosteric heat of adsorption decreased when the concentration increased from $-78 \mathrm{~kJ} \mathrm{~mol}^{-1}$ to $-5.5 \mathrm{~kJ} \mathrm{~mol}^{-1}$; likewise, the immersion enthalpies showed the same trend and varied between -2152 and $82.8 \mathrm{~J} \mathrm{~g}^{-1}$.

At basic $\mathrm{pH}$, the presence of oxygenated groups on activated carbon decreases phenol adsorption capacity due to a strong repulsive effect between phenolate and acidic chemical groups that are ionized with negative charge; however, oxygenated groups of a basic nature, such as pyrones, can contribute to form adsorbate-adsorbent interactions because they are not dissociated $[2,9]$.

Another study [10] indicated that phenol adsorption involves three phases: adsorption at infinite dilution, filling of micropores, and filling of larger micropores. In the first phase, there is a correlation between the number of oxygenated groups and a decrease in adsorption capacity, which is associated with an increase in the affinity of the surface for the solvent, which is corroborated by an increase in the immersion enthalpy in water with respect to the amount of acid groups. This same author affirms that aromatic compounds, such as phenol, present three mechanisms by which adsorption on activated carbon is carried out from the aqueous phase: interactions by dispersion of $\pi$ electrons, formation of hydrogen bonds, and formation of electron donor-acceptor complexes [11].

Most phenol-adsorbent interactions are due to physisorption; however, the oxidative coupling of phenol on activated carbon is associated with chemisorption.

From the thermodynamic point of view, the adsorption of phenol on activated carbon is considered exothermic, with enthalpy values between -6.03 and $-30.4 \mathrm{~kJ} \mathrm{~mol}^{-1}$, according to [5]. The process presents a low energy barrier to be carried out given that the activation energies are around $13 \mathrm{~kJ} \mathrm{~mol}^{-1}$, which confirms that the process is a physisorption. The entropy change values are positive and depend on the surface chemistry of the adsorbent and the chemistry of the solution $[10,11]$.

The adsorption processes have made it possible to address this type of research during the last few years. A great variety of materials, such as activated carbons [12-16], silica $[12,17,18]$, polymeric resins [12,19,20], fly ash [21], clays including kaolinite [22], and zeolites [23-27], have been explored in detail for the removal of phenolic pollutants from wastewater. Among these materials, some authors [12] have reported that materials such as zeolite adsorbents have been regarded as an alternative to activated carbon due to their adsorption-regeneration properties. They say that although they have attracted special attention in sorption processes, their use in this field is limited by their pore size diameter with regards to the size of the organic pollutants [12]. As such, the use of mesoporous materials seems to be promising because of their larger pore volume and diameter, their high surface area, and their regular channel type structures [28,29]. The interest in the potential utilization of mesoporous materials as sorbents is increasing due to the need for economical and efficient adsorbents to remove organic contaminants from wastewater.

According to the literature, the chemical modification of mesoporous adsorbents by introducing functional groups into the matrixes enhances their adsorption capacity for phenol-containing materials [30]. For example, organically functionalized mesoporous silica materials, such as MCM41 and SBA-15, have already been reported by Brunel et al. and Stein et al. [12,31,32]. However, information on mesoporous materials interacting with toxic phenolic compounds is still limited.

In some research published by renowned researchers, Mangrulkar et al. [12,33] have used MCM-41 to remove phenol from an aqueous solution and observed that the removal of phenols from water is strongly dependent on the type of species (dissociated or molecular), as dissociated species are more polar than molecular compounds and interact preferentially 
with water rather than with MCM-41. Their works have allowed them to establish that the most important features involved in the investigation of adsorption phenomenon are: (i) interface characteristics, (ii) the adsorbate-adsorbent interactions, and (iii) adsorption isotherm [12]. It is worth mentioning that the physicochemical mechanisms in these materials are not very well described; no simple theory of adsorption could adequately describe experimental results. The adsorption phenomenon depends on interactions between the surface of the adsorbent and the adsorbed species. These interactions may be due to (i) chemical bonding, (ii) hydrogen bonding, (iii) hydrophobic bonding, or (iv) Van der Waals force. It was observed that the adsorption of substituted benzene depends on the electronic effect of the substituent. However, during the adsorption of dioxane on non-porous, mesoporous, and microporous silica, it was observed that adsorption on microporous silica is governed by pore volume and dimension.

SBA-15 material (Santa Barbara Amorphous No 15) is a mesoporous silica that has been increasing in importance due to its textural properties, regular mesoporous structure, high specific surface area, thermal and mechanical stability, distribution, and pore size. Its high uniformity allows for its potential use in the removal of inorganic and organic contaminants in aqueous solutions [34]. The functionalization of the silica generates an increase in the adsorption capacity because, upon including functional groups, the active sites increase and the conditions on the chemical surface improve [29].

This work was developed with the objective of preparing and functionalizing SBA-15 with polyaniline to increase the capacity to adsorb phenol from the liquid phase, enabling the study of its interactions through the enthalpy of the immersion of solids in benzene, water, and solutions of $0.1 \mathrm{M} \mathrm{NaOH}, 0.1 \mathrm{M} \mathrm{HCl}$, and phenol, and the elucidation of the relationships that exist between the enthalpies of the immersion of silica and its modification, along with its physicochemical properties, such as surface area, total acidity and basicity, and $\mathrm{pH}$ at the point of charge zero. The phenol adsorption capacity of SBA-15 and SBA-15/PA was determined using the adsorption isotherms for aqueous solutions.

\section{Materials and Methods}

\subsection{SBA-15 Synthesis}

SBA-15 was synthesized according to the method reported by Zhao et al. [35]. Initially, $18 \mathrm{~g}$ of pluronic 123 (Sigma-Aldrich, St. Louis, MO, USA) and $135 \mathrm{~g}$ of water were weighed and dissolved, and the mixture was left while stirring for $24 \mathrm{~h}$. This solution was then placed in a water bath at $37^{\circ} \mathrm{C}$, a solution of $\mathrm{HCl}(72 \mathrm{~mL}$ of concentrated hydrochloric acid in $450 \mathrm{~mL}$ of water) was added slowly, and then $42 \mathrm{~mL}$ of TEOS (tetraethylorthosilicate) (Aldrich) was added. Finally, the mixture was left while stirring for $20 \mathrm{~h}$, washed with plenty of water, dried at $70^{\circ} \mathrm{C}$ for $24 \mathrm{~h}$, and calcined at $540{ }^{\circ} \mathrm{C}$ for $6 \mathrm{~h}$.

\subsection{Modification with Polyaniline}

SBA-15 was modified with polyaniline, as reported by Weng et al. [36]. A solution of $42.9 \mathrm{~mL}$ of $0.55 \mathrm{M}$ hydrochloric acid and $1.95 \mathrm{~mL}$ of aniline was prepared, followed by the addition of $2 \mathrm{~g}$ of SBA-15. This was stirred for $30 \mathrm{~min}$ in an ice-water bath at $0{ }^{\circ} \mathrm{C}$, a solution of ammonium persulfate, APS (4.45 g of APS in $19.5 \mathrm{~mL}$ of water), was added dropwise, and the mixture was left to stand for $3 \mathrm{~h}$. Subsequently, it was filtered and washed three times with water, acetone, and a $0.55 \mathrm{M}$ hydrochloric acid solution. Finally, it was dried at $70{ }^{\circ} \mathrm{C}$ for $24 \mathrm{~h}$. The solid obtained was called SBA-15/PA.

\subsection{Textural Characterization}

The surface area and pore volume were determined by weighing approximately $100 \mathrm{mg}$ of the sample, which had been degassed at $250{ }^{\circ} \mathrm{C}$ for $24 \mathrm{~h}$, followed by $\mathrm{N}_{2}$ fission at $77 \mathrm{~K}$ on a Quantachrome Autosorb IQ2 sortometer. The surface area was determined by 
applying the Brunauer-Emmett-Teller (BET) model. The most common form of the BET equation is:

$$
\frac{\frac{P}{P_{o}}}{n\left(1-\frac{P}{P_{0}}\right)}=\frac{1}{n_{m} C}+\frac{C-1}{n_{m} C}\left(\frac{P}{P_{o}}\right) ; C=\operatorname{Exp}\left(\frac{q 1-q 2}{R T}\right)
$$

where $n$ is the specific amount of gas adsorbed at the relative pressure $P / P_{0}, n_{m}$ is the adsorption capacity in the monolayer, $P$ is the pressure, $P_{o}$ is the saturation pressure of a substance that is adsorbed at the adsorption temperature, and $C$ is the BET constant that is exponentially related to the monolayer adsorption energy [37]. Micropore volume $\left(\mathrm{V}_{\mathrm{o}}\right)$ was calculated using Dubinin-Radushkevich (D-R) equation; mesopore volume $\left(\mathrm{V}_{\text {meso }}\right)$, total volume, and pore diameter were calculated using the density functional theory (DFT) method.

\subsection{Chemical Characterization}

The total acidity and basicity were determined according to the method proposed by Boehm [38] with modifications. First, $0.1 \mathrm{~g}$ of the sample was mixed with $50 \mathrm{~mL}$ of $0.05 \mathrm{M} \mathrm{NaOH}$ and $50 \mathrm{~mL} 0.05 \mathrm{M} \mathrm{HCl}$. The mixture was left under constant stirring for five days. Subsequently, an aliquot of $10 \mathrm{~mL}$ of the solution was titrated with previously standardized acid or base using a CG $840 \mathrm{~B}$ Schott automatic titrator. The zero-charge point $\left(\mathrm{pH}_{\mathrm{pzc}}\right)$ was determined using the mass titration method. Quantities between 0.1 and $0.6 \mathrm{~g}$ of the samples were weighed, and $10 \mathrm{~mL}$ of $0.1 \mathrm{M} \mathrm{NaCl}$ was added. They were left under constant stirring for $48 \mathrm{~h}$; then, the $\mathrm{pH}$ of each solution was measured with a $\mathrm{pH}$ meter, a CG 840B Schott [39].

\subsection{Determination of Immersion Enthalpy}

The immersion enthalpies of SBA-15 and its modification in benzene, water, and solutions of $0.1 \mathrm{M} \mathrm{NaOH}, 0.1 \mathrm{M} \mathrm{HCl}$, and phenol $\left(100 \mathrm{mg} \mathrm{L}^{-1}\right)$ were determined using a heat-conduction microcalorimeter [40-45]. For the determinations, $0.1 \mathrm{~g}$ of a sample was weighed and placed in a glass vial that was fitted inside the equipment cell. Then, $10 \mathrm{~mL}$ of the liquid was placed in a stainless steel cell, the temperature was stabilized, and thermal recording was initiated by an electrical potential signal from the sensors; then, the sample was immersed in the liquid. The resulting thermal changes were recorded, and, finally, electrical calibration was performed.

\subsection{Adsorption Isotherms}

In order to investigate the influence of adsorption conditions on the adsorption ability of mesoporous SBA-15 and SBA-15/PA composites, including the initial concentration of phenol, adsorption temperature and $\mathrm{pH}$ value, batch adsorption experiments were conducted previously (these results are not shown here; they were taken as a basis to establish the experimental conditions of this investigation). Firstly, a series of phenol aqueous solutions with concentrations ranging from 20 to $150 \mathrm{mg} \mathrm{L}^{-1}$ were prepared by dissolving different amounts of phenol in deionized water. Then, a series of phenol aqueous solutions with the same phenol concentration $\left(150 \mathrm{mg} \mathrm{L}^{-1}\right)$ and various $\mathrm{pH}$ values in the range of 2-10 were also prepared by introducing different amounts of $\mathrm{HCl}$ or $\mathrm{NaOH}$ solutions. Then, for each experiment, the adsorbent was separated from the mixture by centrifugation, and the residual concentration of phenol solution was measured using an ultraviolet-visible (UV-vis) spectrometer (Thermo Nicolet Nexus) at a characteristic adsorption wavelength of $271.0 \mathrm{~nm}$. In addition, for studying the effect of adsorption temperatures on the uptake capacity of the mesoporous composite, $0.06 \mathrm{~g}$ of adsorbent was added to $100 \mathrm{~mL}$ of $150 \mathrm{mg} \mathrm{L}^{-1}$ phenol solution and stirred at $15,25,30,35$, and $40{ }^{\circ} \mathrm{C}$, respectively. Then, the residual phenol concentrations were measured using the same method as mentioned above. Moreover, the adsorption capacity of pristine SBA-15 silica was also analyzed for studying the effect of polyaniline modification on the removal of phenol. Typically, $0.02 \mathrm{~g}$ of pristine SBA-15 and SBA-15/PA composite was, respectively, 
added into $100 \mathrm{~mL}$ of phenol solutions with initial concentrations of $20-150 \mathrm{mg} \mathrm{L}^{-1}$ under stirring at $25^{\circ} \mathrm{C}$. After $15 \mathrm{~h}$, the adsorbent was separated by centrifugation, and the residual resorcinol concentrations were measured using the UV-vis spectrometer. Finally, they were left stirring for 58 hours until they reached equilibrium. The samples were filtered and the phenol concentrations were determined on a UV-Vis Thermo Nicolet Nexus spectrophotometer at $271 \mathrm{~nm}$. The equilibrium concentration, $C_{e}\left(\mathrm{mg} \mathrm{L}^{-1}\right)$ and the amounts adsorbed on the adsorbent at equilibrium, $q_{e}\left(\mathrm{mg} \mathrm{g}^{-1}\right)$, were calculated. The initial $\mathrm{pH}$ of phenol solutions is 6.9 in SBA-15 and 3.0 in SBA-15/PA, and these values were maintained during each of the experiments.

\section{Results}

\subsection{Textural Characterization}

Figure 1 shows the nitrogen adsorption isotherms obtained for SBA-15 and SBA15/PA; the samples presented type IV(a) isotherms according to the updated IUPAC classification [39-41]. At medium relative pressures, capillary condensation began and H1-type hysteresis loops were generated, which are associated with mesoporous solids with cylindrical pore channels. For SBA-15/PA, the hysteresis loop is H5 type, which is associated with pore structures containing open and partially blocked mesopores. The incorporation of polyaniline in the pores of the silica explains the decrease in the amount of nitrogen adsorbed; this behavior is due to the limitation of the diffusion of nitrogen molecules that generate the surface groups located in the openings of the pores [42].

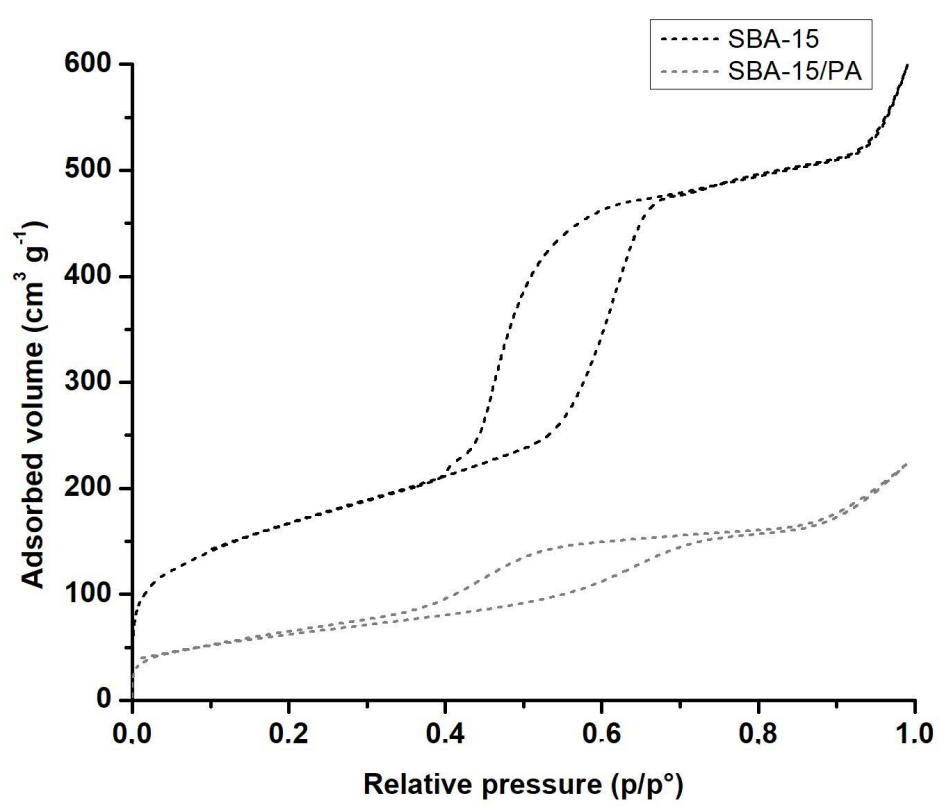

Figure 1. Nitrogen adsorption isotherms at $77 \mathrm{~K}$ for SBA-15 and SBA-15/PA.

The textural parameters of the BET surface area, micropore volume $\left(\mathrm{V}_{\mathrm{o}}\right)$, mesopore volume $\left(\mathrm{V}_{\text {meso }}\right)$, total volume, and pore diameter were calculated from the experimental data of the $\mathrm{N}_{2}$ adsorption-desorption isotherm and are shown in Table 1. The surface area value for SBA-15 was $654.5 \mathrm{~m}^{2} \mathrm{~g}^{-1}$ and its pore diameter was $6.08 \mathrm{~nm}$; after the surface modification, the surface area and pore diameter values were reduced to $215.3 \mathrm{~m}^{2} \mathrm{~g}^{-1}$ and $5.28 \mathrm{~nm}$, respectively. Likewise, the total pore volume changed from 0.84 to $0.33 \mathrm{~cm}^{3} \mathrm{~g}^{-1}$ due to the partial blocking of the pore channels of SBA-15 by polyaniline, supporting the idea that polymerization took place primarily within the pores of SBA-15 [42-44]. 
Table 1. Textural parameters of SBA- 15 and SBA-15/PA determined from the $\mathrm{N}_{2}$ isotherms at $77 \mathrm{~K}$.

\begin{tabular}{cccccc}
\hline Sample & $\begin{array}{c}\text { Surface Area } \\
\left(\mathbf{m}^{\mathbf{2}} \mathbf{g}^{-\mathbf{1}} \mathbf{)} \mathbf{B E T}\right.\end{array}$ & $\begin{array}{c}\mathbf{V}_{\mathbf{o}} \\
\left(\mathbf{c m}^{\mathbf{3}} \mathbf{g}^{-\mathbf{1}}\right)\end{array}$ & $\begin{array}{c}\mathbf{V}_{\text {meso }} \\
\left(\mathbf{c m}^{\mathbf{3}} \mathbf{g}^{-\mathbf{1}}\right)\end{array}$ & $\begin{array}{c}\text { Total } \mathbf{~} \\
\left(\mathbf{c m}^{\mathbf{3}} \mathbf{g}^{-\mathbf{1}}\right)\end{array}$ & $\begin{array}{c}\text { Average Pore } \\
\text { Diameter } \mathbf{( n m})\end{array}$ \\
\hline SBA-15 & 655 & 0.22 & 0.61 & 0.84 & $6.08 \pm 0.06$ \\
SBA-15/PA & 215 & 0.07 & 0.26 & 0.33 & $5.28 \pm 0.05$ \\
\hline
\end{tabular}

The precision for the surface area values was $\pm 1 \mathrm{~m}^{2} \mathrm{~g}^{-1}$, and that for the pore volume was $\pm 0.01 \mathrm{~cm}^{3} \mathrm{~g}^{-1}$, according to the characteristics of the Quantachrome Autosorb IQ2 sortometer.

\subsection{Chemical Characterization}

Using the methodology proposed by Boehm, the acid-base character of the surface of the silica was determined depending on the amount of acidic or basic sites that it contained. Table 2 shows the results obtained for the acidity, basicity, and the point of zero-charge for SBA-15 and SBA-15/PA. SBA-15 has total acid groups of 0.026 meq $^{-1}$ and a $\mathrm{pH}$ at the point of zero charge of 6.5. According to these values, the acidity of the surface is related to the deprotonation of the silanols; after their modification, there is evidence of a decrease in the amount of acid sites to $0.011 \mathrm{meq} \mathrm{g}^{-1}$ and in the $\mathrm{pH}_{\mathrm{pzc}}$ to 3.0 , these values being attributed to the decrease in silanol groups present on the surface of SBA-15. The $\mathrm{pH}$ at the point of zero charge of the two samples is acidic, such that if the solids were put in contact with solutions whose $\mathrm{pHs}$ were lower than the $\mathrm{pH}_{\mathrm{pzc}}$, the charges on their surfaces would be positive, on average $[45,46]$.

Table 2. Acidity, basicity, and $\mathrm{pH}$ at zero charge point of SBA-15 and its modification.

\begin{tabular}{cccc}
\hline Sample & Acidic Sites $\left(\mathbf{m e q}^{\mathbf{- 1}}\right)$ & Basic Sites $\left(\mathbf{m e q} \mathbf{g}^{-\mathbf{1}}\right)$ & $\mathbf{p H}_{\mathbf{p z c}}$ \\
\hline SBA-15 & $0.026 \pm 1.0 \times 10^{-4}$ & $0.010 \pm 1.2 \times 10^{-4}$ & $6.5 \pm 0.01$ \\
SBA-15/PA & $0.011 \pm 1.2 \times 10^{-4}$ & $0.006 \pm 0.8 \times 10^{-4}$ & $3.0 \pm 0.01$ \\
\hline
\end{tabular}

\subsection{Immersion Enthalpy Measurements}

Immersion enthalpy is a thermodynamic parameter that correlates the pore structure and the surface chemistry of the solid. Table 3 shows the values obtained in the calorimetric determinations; all the immersion enthalpies are negative, which indicates that these processes are exothermic. Figures $2-4$ show the electric potential curves as a function of time for the immersion process of samples and their modification into benzene, water, $\mathrm{NaOH}(0.1 \mathrm{M},) \mathrm{HCl}(0.1 \mathrm{M})$, and phenol solution $\left(100 \mathrm{mgL}^{-1}\right)$ to evaluate the interaction between the silica, the solvents, and the solutions used. This information allows the magnitude of the interaction in the adsorption to be established.

Table 3. Enthalpies of immersion for SBA-15 and its modification in water, benzene, and solutions of $\mathrm{HCl}, \mathrm{NaOH}$, and phenol.

\begin{tabular}{|c|c|c|c|c|c|}
\hline Sample & $\begin{array}{c}-\Delta \mathbf{H}_{\text {Exp. }} \\
\text { Water }\left(\mathrm{J} \mathrm{g}^{-1}\right)\end{array}$ & $\begin{array}{c}-\Delta \mathrm{H}_{\text {Exp. }} \\
\text { Benzene } \\
\left(\mathrm{Jg}^{-1}\right)\end{array}$ & $\begin{array}{c}-\Delta \mathrm{H}_{\text {Exp. }} \mathrm{HCl} \\
\quad\left(\mathrm{J} \mathrm{g}^{-1}\right)\end{array}$ & $\begin{array}{c}-\Delta \mathrm{H}_{\text {Exp. }} \\
\mathrm{NaOH} \\
\left(\mathrm{J} \mathrm{g}^{-1}\right)\end{array}$ & $\begin{array}{c}-\Delta H_{\text {Exp. }} \\
\text { Phenol Solution } \\
\left(\mathrm{J} \mathrm{g}^{-1}\right)\end{array}$ \\
\hline SBA-15 & $31.2 \pm 0.5$ & $28.1 \pm 0.4$ & $62.2 \pm 0.8$ & $174.1 \pm 2.3$ & $41.0 \pm 0.6$ \\
\hline SBA-15/PA & $20.4 \pm 0.3$ & $15.1 \pm 0.2$ & $58.7 \pm 0.8$ & $167.7 \pm 2.2$ & $18.5 \pm 0.3$ \\
\hline
\end{tabular}

Figure 2 shows the potentiograms from the immersion calorimetry in water and benzene of SBA-15 and its modification. The polarity of the surface of the silicas could be evaluated based on the fact that the proportion of hydrophobicity and hydrophilicity of a surface can be estimated using the relationship with the enthalpies of immersion in a polar and a nonpolar liquid, such as water and benzene. As the values of the enthalpy of immersion in water of SBA-15 and SBA-15/PA were greater than those of the enthalpy of 
immersion in benzene, the surfaces were considered hydrophilic. However, the formation of hydrogen bonds between the water molecules and the silanol groups of SBA-15 generated an enthalpy value of $31.2 \mathrm{~J} \mathrm{~g}^{-1}$, and upon reducing the amount of silanol groups in SBA-15/PA by shielding the polyaniline molecules located in the polar sites of the surface of the silica, the enthalpy of immersion in water was reduced to $20.4 \mathrm{~J} \mathrm{~g}^{-1}$ [39-49].

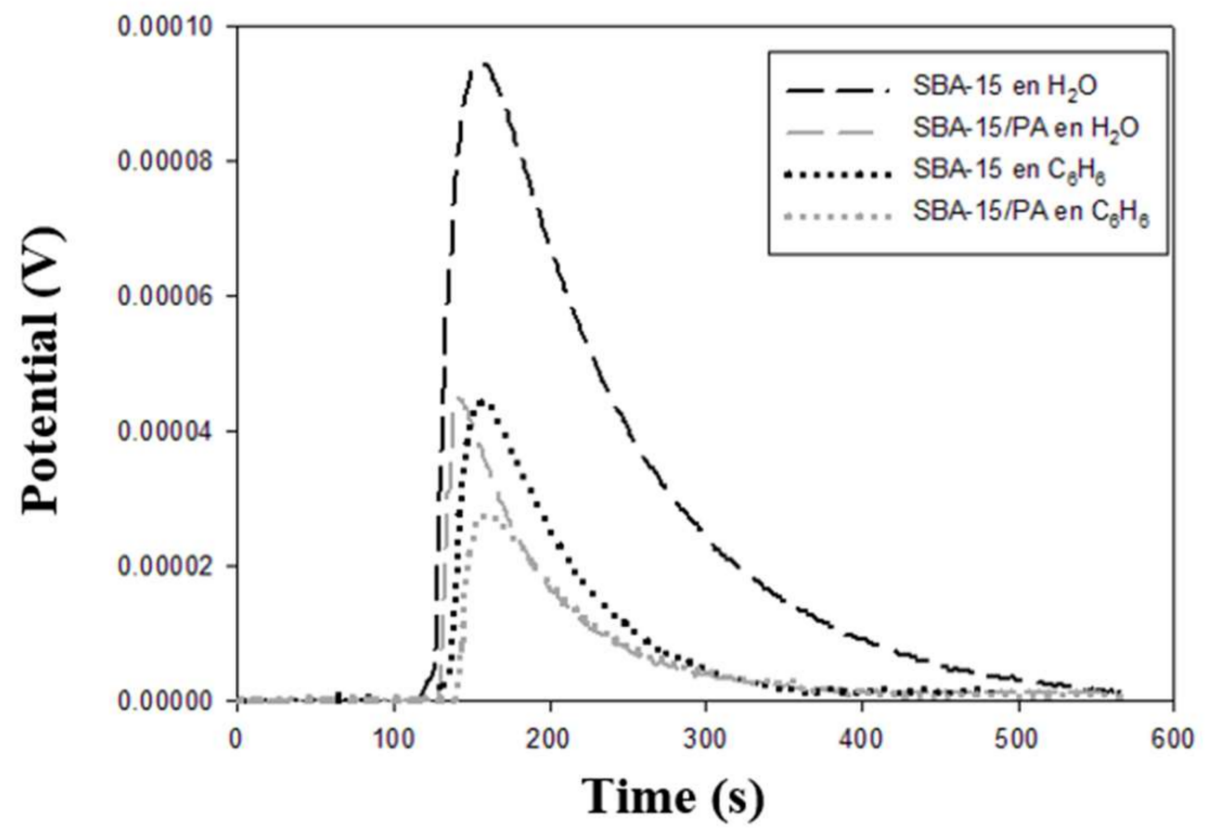

Figure 2. Potentiogram of immersion of the SBA-15 and its modification in water and benzene.

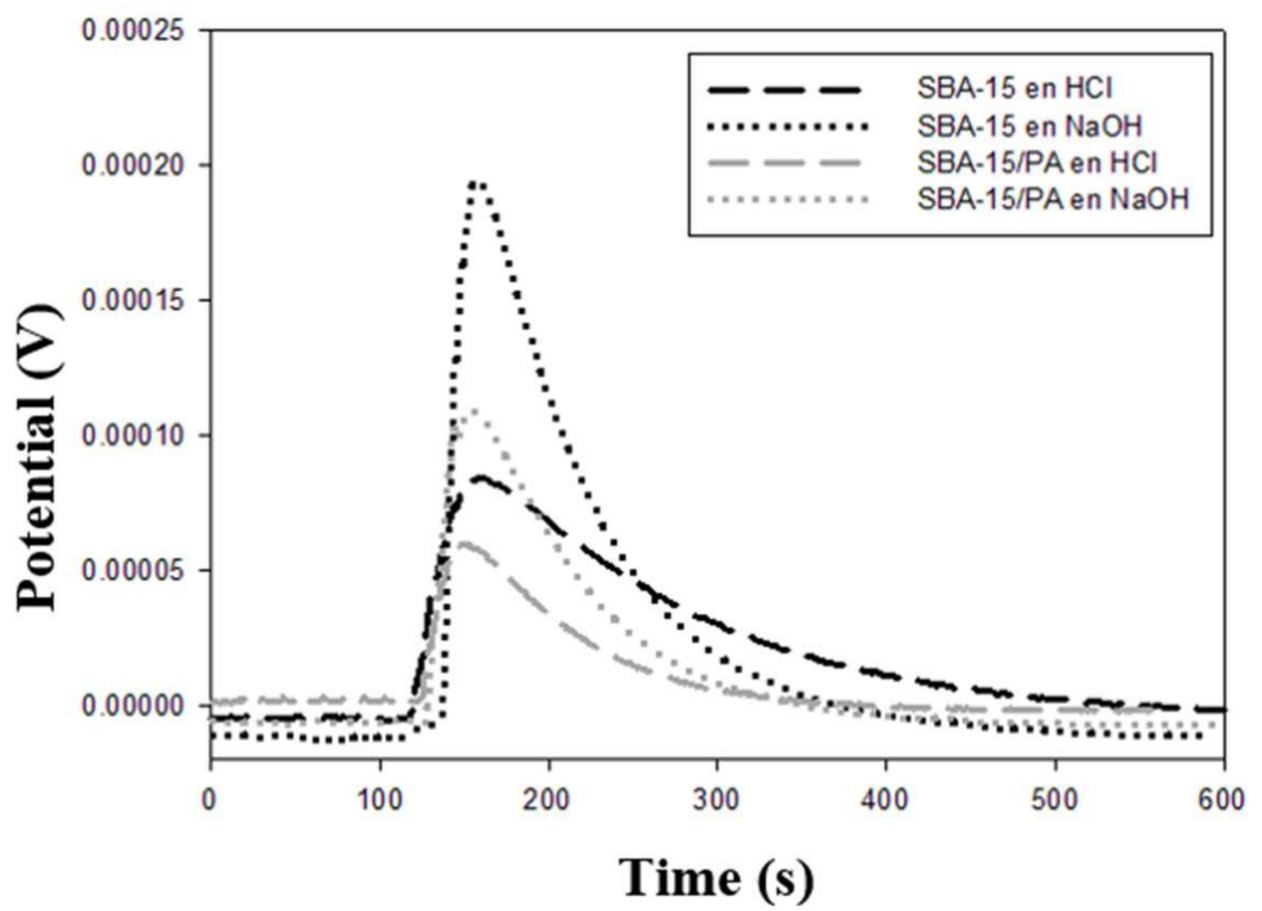

Figure 3. Immersion potentiogram for SBA-15 and its modification in $\mathrm{HCl}$ and $\mathrm{NaOH}$. 


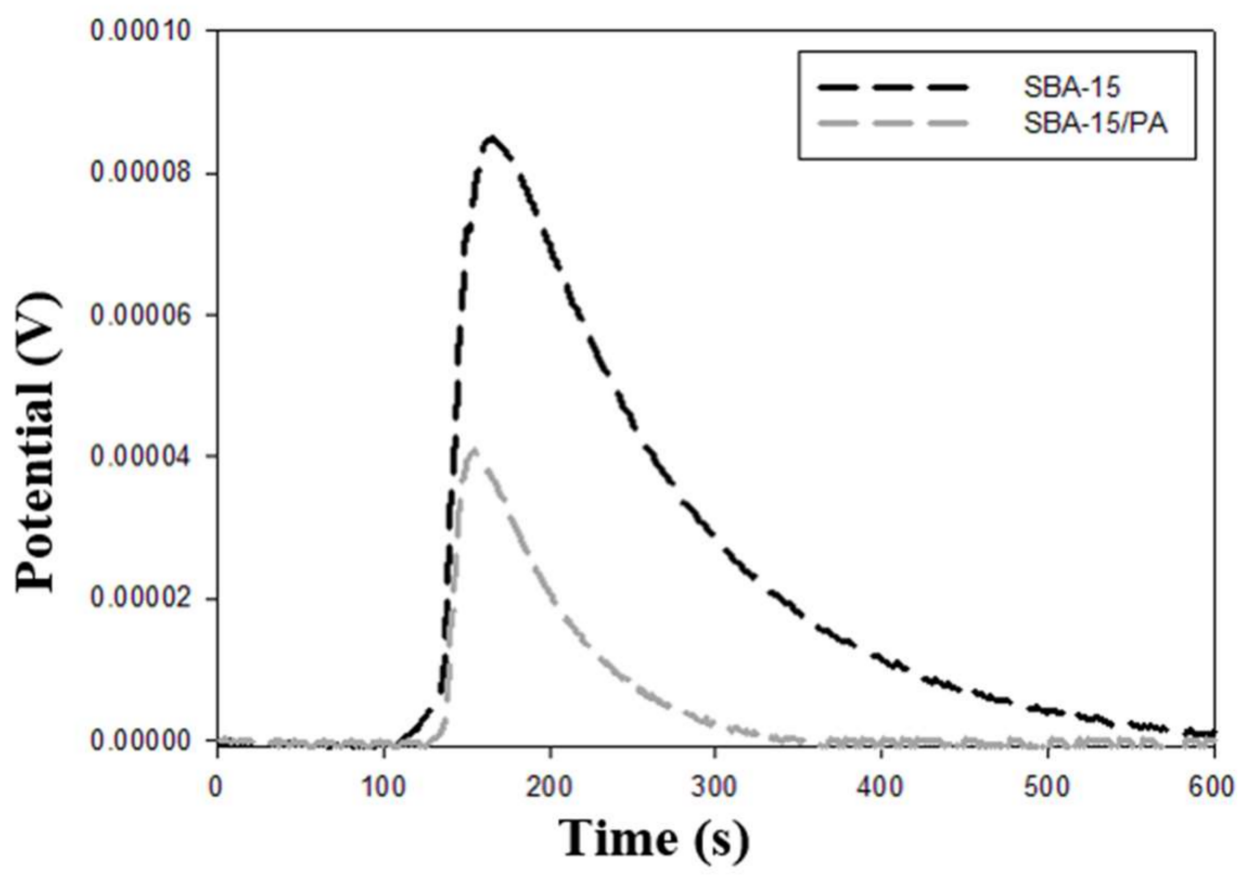

Figure 4. Immersion potentiogram for SBA-15 and its modification in $100 \mathrm{mg} \mathrm{L}^{-1}$ phenol solution.

The absolute values of the enthalpy of SBA-15 and SBA-15/PA were higher for immersion in the sodium hydroxide solution, as observable in Figure 3, confirming a greater interaction with the acidic sites of the silicas. As the enthalpy of immersion of the silicas in the solutions were related to the acidity and total basicity of the former, it is evident that, in the case of the immersion enthalpy being a function of the content of acid groups, there was an increase in the value of the enthalpy of immersion of SBA- 15 when the acidity increased, with a value of $0.026 \mathrm{meq} \mathrm{g}^{-1}$, and an immersion enthalpy in $\mathrm{NaOH}$ of $174.1 \mathrm{~J} \mathrm{~g}^{-1}$, decreasing after functionalization with polyaniline to values of $0.011 \mathrm{meq} \mathrm{g}^{-1}$ and $167.7 \mathrm{~J} \mathrm{~g}^{-1}$. With respect to the basic groups, it should be noted that they were related to the values for the immersion enthalpy of the silicas in $\mathrm{HCl}$ solution, since the values for the basic groups were lower than those for the acid groups. The same was observed with the values of the immersion enthalpy in $\mathrm{HCl}$ being lower than the enthalpy in $\mathrm{NaOH}$ [41,49-51].

Another characteristic of silicas is the $\mathrm{pH}$ at the point of zero charge, $\mathrm{pH}_{\mathrm{pcc}}$, which establishes the charge on the surface of the materials and is related to surface chemistry, and which, in turn, affects the energetic interactions that occur between the solid and the immersion liquid. For this reason, it corresponds to the enthalpy of immersion in benzene and a linear behavior is obtained; as the value of the enthalpy of immersion increases, the $\mathrm{pH}$ at the point of zero charge also increases, with $28.1 \mathrm{~J} \mathrm{~g}^{-1}$ being the immersion enthalpy of SBA-15, with a $\mathrm{pH}_{\mathrm{pcc}}$ of 6.5 ; for SBA-15/PA, the enthalpy decreases to $15.1 \mathrm{~J} \mathrm{~g}^{-1}$, as does the $\mathrm{pH}_{\mathrm{pcc}}$ to 3.0 [47-49].

There is a directly proportional relationship between the enthalpy of immersion and the surface area of the silicas, with the greater $28.1 \mathrm{~J} \mathrm{~g}^{-1}$ enthalpy of immersion for SBA-15, because when there is a wider space for the entrance of molecules, greater interaction of the adsorbate with the porous structure is generated. The immersion enthalpy value for SBA-15/PA decreased to $-15.1 \mathrm{~J} \mathrm{~g}^{-1}$. This shows that there was a reduction in porosity due to the fixation of the functional groups on the surface [45-49].

The degree and nature of the interactions at the solid-liquid interface in processes such as adsorption can be determined using the immersion enthalpy, because, for some molecules, it can vary according to the specific interactions between the immersion liquid and the surface of the solid. The immersion enthalpy of SBA-15 in the $100 \mathrm{mg} \mathrm{L}^{-1}$ phenol solution was higher than that of SBA-15/PA. Figure 4 shows that the thermal effect obtained for SBA-15 was high and corresponded to the sum of various interactions, such as the 
wetting of the solid surface by the solvent, the interaction of the solvents with the chemical groups on the surface, and the interaction of phenol with the surface and its groups. In SBA-15/PA, the access of the molecules to the surface decreased in such a way that there was a considerably low thermal effect; however, it continued to present an exothermic enthalpy, correlated with the processes of the interaction of the aniline monomers and the surface of the solid. The adsorbed amount and immersion enthalpy were affected by the contents of total acid and base groups on the surface of SBA-15 and its modification. It is known that, upon decreasing the content of acid groups, the adsorbed amount of the phenolic compound increased [45-49].

\subsection{Adsorption Isotherms}

In order to evaluate the effectiveness of the adsorbents, the equilibrium phenol adsorption $\left(q_{e}\right)$ was studied as a function of the equilibrium concentration $\left(C_{e}\right)$. Adsorption isotherms are modeled by different adsorption isotherms from aqueous solutions.

Adsorption isotherms from aqueous solutions

There are several theoretical models for the description of adsorption isotherms with different considerations, such as the starting hypotheses and the number of characteristic parameters of each of them. The models used in adsorption studies in single-component solid-liquid systems are related to thermodynamic models obtained from theoretical adsorption models based on the thermodynamic properties of the adsorbent and the fluid phase. The others are semi-empirical models, which are the result of an adjustment of experimental data to certain mathematical functions, although with a thermodynamic basis. The models commonly used for the adjustment and interpretation of the experimental data obtained in adsorption studies for solid-liquid single-component systems are detailed below.

Two-parameter isotherm models.

\subsubsection{Langmuir Model}

This is an empirical model that assumes monolayer adsorption and uniform adsorption energy on the surface [50-52]. There is no transmigration of the adsorbate in the plane of the surface [31]. Adsorption only occurs in a finite and fixed number of defined and localized sites that are identically equivalent and in which there are no lateral interactions or steric hindrance between the same adsorbed molecules on the adjacent sites [50]. Adsorption is homogeneous and each molecule has constant enthalpy and activation energy of sorption (all sites have the same affinity for adsorbate) [50-52].

$$
q_{e}=\frac{q_{m} K_{L} C_{e}}{1+K_{L} C_{e}}
$$

where $q_{e}=$ the amount of solute adsorbed per unit weight of adsorbent at equilibrium $\left(\mathrm{mg} \mathrm{g}^{-1}\right), C_{e}=$ the equilibrium concentration of solute in solution volume $\left(\mathrm{mg} \mathrm{L}^{-1}\right)$, $q_{m}=$ the maximum adsorption capacity $\left(\mathrm{mg} \mathrm{g}^{-1}\right)$, and $K_{L}=$ the adsorption equilibrium constant of Langmuir $\left(\mathrm{L} \mathrm{mg}^{-1}\right)$.

\subsubsection{Freundlich Model}

The equation being exponential, the model assumes that the adsorbate concentration increases on the surface of the adsorbent and that it is a multilayer adsorption [53,54]. It describes reversible and non-ideal adsorption with non-uniform distribution of heat of adsorption and affinity on the heterogeneous surface [53]. The amount adsorbed is the sum of the adsorption of all the sites.

$$
q_{e}=K_{F} C_{e}^{1 / n}
$$

where $q_{e}=$ the amount of solute adsorbed per unit weight of adsorbent at equilibrium $\left(\mathrm{mg} \mathrm{g}^{-1}\right), C_{e}=$ the equilibrium concentration of solute in solution volume $\left(\mathrm{mg} \mathrm{L}^{-1}\right)$, $K_{F}=$ the Freundlich constant related to the relative adsorption capacity of the adsorbent 
$\left(\mathrm{mg}^{1-(1 / n)} \mathrm{L}^{1 / n} \mathrm{~g}^{-1}\right)$, and $n=$ the heterogeneity factor, related to the constant that indicates the intensity of the adsorption. If $n=1$, it is a linear adsorption. If $n>1$, it is a physical adsorption and it is favorable. If $n<1$ it is a chemical adsorption. On the other hand, if the value of $1 / n<1$ indicates a normal Langmuir-type isotherm and if $1 / n>1$, cooperative adsorption is indicated.

Two-parameter isotherm models.

\subsubsection{Sips Model}

The Sips model is a combined form of the Langmuir and Freundlich expressions deduced to predict systems with heterogeneous adsorption and overcome the limitations at high concentrations of the Freundlich equation [55-58]. At low concentrations, the adsorbate is reduced to the Freundlich isotherm, whereas at high concentrations a monolayer adsorption is predicted, characteristic of the Langmuir isotherm. As a general rule, the parameters of the equation are mainly governed by adsorption conditions, such as $\mathrm{pH}$, temperature, and concentration $[55,56]$.

$$
q_{e}=\frac{q_{m S}\left(K_{S} C_{e}\right)^{\frac{1}{n_{S}}}}{1+\left(K_{S} C_{e}\right)^{\frac{1}{n_{S}}}}
$$

where $q_{e}=$ the amount of solute adsorbed per unit weight of adsorbent at equilibrium $\left(\mathrm{mg} \mathrm{g}^{-1}\right), C_{e}=$ the equilibrium concentration of solute in solution volume $\left(\mathrm{mg} \mathrm{L}^{-1}\right)$, $q_{m s}=$ the Sips maximum adsorption capacity $\left(\mathrm{mg} \mathrm{g}^{-1}\right), K_{s}=$ the Sips equilibrium constant, and $n_{S}=$ the Sips model exponent.

\subsubsection{Tóth Model}

This is an empirical equation modified from the Langmuir equation that reduces the error between the experimental data and the predicted values of the equilibrium adsorption data [54-58]. The application of this equation is more appropriate for multilayer adsorption and for heterogeneous adsorption systems that satisfy the low and high concentration ranges $[57,58]$. Its correlation assumes an asymmetric quasi-Gaussian distribution, with most sites having an adsorption energy lower than the maximum peak or the mean value $[57,58]$.

$$
q_{e}=q_{m T} \frac{C_{e}}{\left[\frac{1}{K_{T}}+C_{e}^{m_{T}}\right]^{1 / m_{T}}}
$$

where $q_{e}\left(\mathrm{mmol} \mathrm{g}^{-1}\right)$ and $C_{e}\left(\mathrm{mmol} \mathrm{L}^{-1}\right)$ have the same meaning as in the above equations, $q_{m T}\left(\mathrm{mmol} \mathrm{g}^{-1}\right)=$ the Tóth maximun adsorption capacity, $K_{T}=$ the Tóth equilibrium constant, and $m T=$ the model exponent. When $m T$ is equal to 1 , Toth's equation is reduced to Langmuir's equation, with which it can be deduced that this parameter is related to the heterogeneity of the system.

\subsubsection{Redlich-Peterson Model}

Similar to the Sips model, this takes into account the characteristics of the Langmuir and Freundlich isotherms in a single equation, indicating that the adsorption mechanism is a combination of both models. Due to its versatility, it allows the representation of an adsorption system in equilibrium for a wide range of concentrations and can be applied for both homogeneous and heterogeneous systems. The model is represented by the following equation $[57,58]$.

$$
q_{e}=\frac{K_{R P} C_{e}}{1+\alpha_{R P} C_{e}^{\beta}}
$$

where $K_{R P}\left(\mathrm{~L} \mathrm{~g}^{-1}\right), \dashv_{R P}\left(\mathrm{~L} \mathrm{mg}^{-1}\right)^{-\beta}$ and the exponent $\beta$ (dimensionless) are RedlichPeterson parameters. The $\beta$ value is between 0 and 1 and it determines the degree of heterogeneity of the surface. This equation is transformed into a linear isotherm (Henry's 
equation) at low surface coverage $(\beta=0)$, it is reduced to the Langmuir isotherm when $\beta=1$, and becomes the Freundlich isotherm when $K_{R P}$ y $\alpha_{R P}>>1$ y $\beta=1$.

The results shown in Figure 5 for the SBA-15 and SBA-15/PA samples were analyzed and evaluated according to the aforementioned models using the ANOVA analysis of variance optimization method, included in the Sigma-Plot ${ }^{\circledR}$ v.10.0 software for each adjustment function according to each model. These results correspond to experimental data in the equilibrium data of phenol that were adjusted with the mathematical expressions which represent the corresponding isotherms in their linear form for each model, and their results are presented in Tables 4 and 5 .

The associated error analysis shows that the Freundlich model is the most appropriate for representing the adsorption process, as it had excellent correlations of $\mathrm{R}^{2}>0.99$ and low standard mean error percentages, $\varepsilon<1.2 \%$. Likewise, the Langmuir model, with $\mathrm{R}^{2}$ correlations greater than 0.97 and $\varepsilon$ errors less than $2.9 \%$, can represent the isotherms in an acceptable manner, as shown when representing the experimental data in Figure 5 by the dotted lines in the experimental adsorption data. The measure of the heterogeneity of the surface $1 / \mathrm{n}$ in the Freundlich model in SBA-15/PA is 0.3296 ; as this is less than 1, it is established that the adsorption process is favorable and indicates that the surface is heterogeneous; the relative adsorption capacity of the SBA-15 modified with polyaniline is 24.07 times higher than the relative adsorption capacity of SBA-15. The maximum adsorption capacity values calculated using the Langmuir model were 138 and $85.54 \mathrm{mg} \mathrm{g}^{-1}$ for SBA-15/PA and SBA-15, respectively, again indicating an increase in adsorption effectiveness upon the inclusion of the polyaniline groups in the structure.

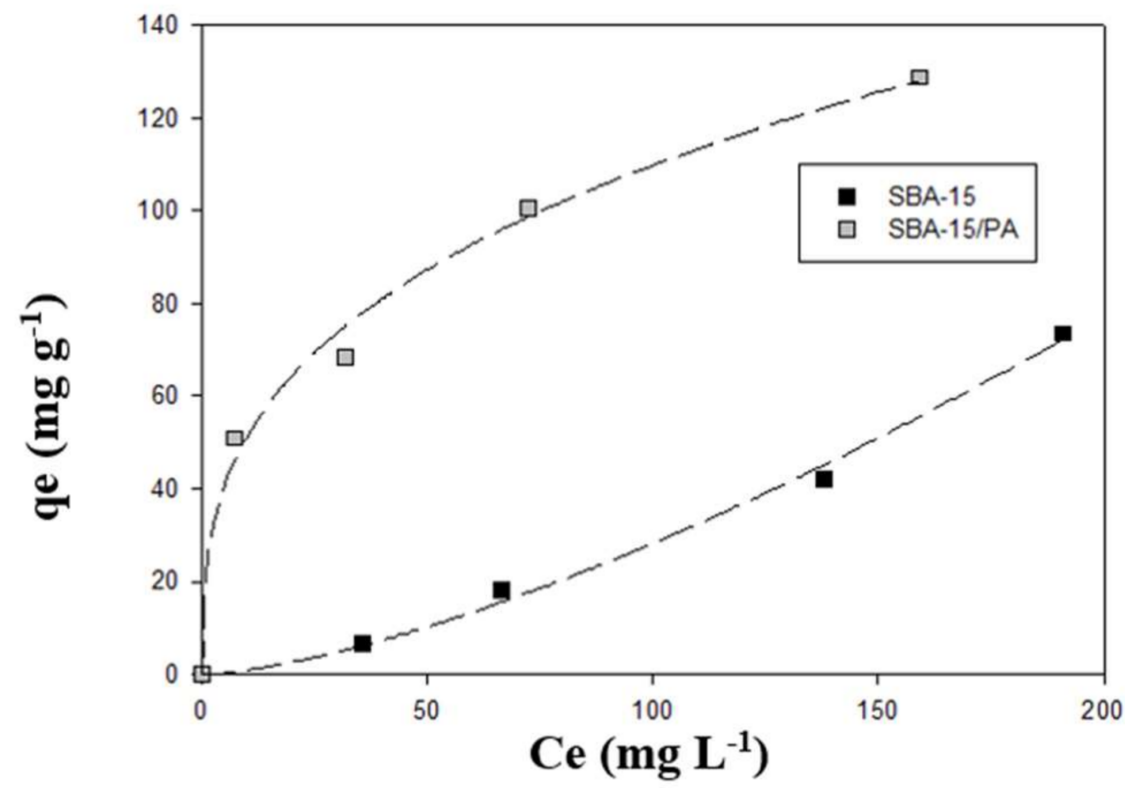

Figure 5. Isotherms for phenol adsorption from experimental data from aqueous solutions on silica and its modification.

Table 4. Langmuir and Freundlich (two-parameter isotherms) parameters on silica and its modification.

\begin{tabular}{cccc}
\hline Model & Parameter & SBA-15 & SBA-15/PA \\
\hline Langmuir & $q_{m}$ & 85.54 & 138 \\
& $K_{L}$ & 0.0024 & 0.0463 \\
$\mathrm{R}^{2}$ & 0.992 & 0.972 \\
& $\varepsilon(\%)$ & 2193 & 2929 \\
\multirow{2}{*}{ Freundlich } & $K_{F}$ & 0.0347 & 24.07 \\
& $1 / \mathrm{n}$ & 1.4552 & 0.3296 \\
& $\mathrm{R}^{2}$ & 0.9971 & 0.9962 \\
& $\varepsilon(\%)$ & 1289 & 1376 \\
\hline
\end{tabular}


Table 5. Sips, Tóth and Redlich-Peterson (three-parameter isotherms) parameters on silica and its modification.

\begin{tabular}{ccc}
\hline Model Isotherms Parameters & SBA-15 & SBA-15/PA \\
\hline Sips & & \\
$q_{m s}\left(\mathrm{mg} \mathrm{g}^{-1}\right)$ & 67.37 & 78.97 \\
$K_{s}\left(\mathrm{~L}^{\mathrm{m}} \mathrm{mg}^{-\mathrm{m}}\right)$ & $4.32 \times 10^{-4}$ & $3.23 \times 10^{-3}$ \\
$m_{S}$ & 1988 & 0.902 \\
$\mathrm{R}^{2}$ & 0.9769 & 0.9804 \\
$\mathrm{Tòth}\left(\mathrm{mg} \mathrm{g}^{-1}\right)$ & 67.34 & \\
$K_{T}$ & 0.467 & 96.45 \\
$m_{T}$ & 3.691 & 0.134 \\
$\mathrm{R}^{2}$ & 0.9587 & 0.928 \\
Redlich-Peterson $_{K_{R P}}$ & & 0.9601 \\
$\alpha$ & 6.4326 & 3.6784 \\
$\beta$ & 1.6785 & 1.7865 \\
$\mathrm{R}^{2}$ & 0.2745 & 0.3215 \\
\end{tabular}

The phenol isotherms in SBA-15 and SBA-15/PA are shown in Figure 5. It was observed that the adsorption order in terms of the amount adsorbed was greater in SBA-15/PA than in SBA-15. This can be explained by the fact that large amounts of polyaniline macromolecules were fixed on the walls of the pores of SBA-15, and since phenol is a weak acid and polyaniline a weak base, acid-base interactions occurred in the adsorption process. SBA-15/PA, having an acidic surface, interacts with the phenol solution, while the amino groups of the aniline interact with the hydroxyl group through hydrogen bonds [49-58]. When you have the value of $n(0<1 n<1)$ for the Freundlich model, this suggests that the adsorbent surface is heterogeneous. In this study, it is interesting that by modifying the SBA-15 with polyaniline, one went from a surface that was not homogeneous to a more homogeneous one. This had an impact on the adsorption capacity of phenol.

In summary, it can be said that for the two-parameter models, the sample with the best fit between these two models was the SBA-15 sample, and, under the experimental conditions of this research work, there is a greater fit to the Freundlich model compared to Langmuir's, taking from now on the regression coefficient $R^{2}$ as a criterion for the analysis of all models.

Regarding the three-parameter models, neither of the two shows a behavior that allows an affirmation that one fits better than one of the abovementioned models, despite having three parameters. If we slightly amplify the $\mathrm{R}^{2}$ criterion in qualitative way, it can be said that the SBA-15/PA sample has a relative fit to the Sips model.

This result is consistent if it is taken into account that the Sips model is derived from a mathematical treatment between the Langmuir and Freundlich models. For this reason, the adsorption of phenol on the SBA-15/PA samples and even that of SBA-15 can be explained by this model. This result turns out to be very interesting and should be further explored at different phenol concentrations and temperatures.

The experimental results with the adsorbents at a constant temperature in equilibrium conditions were tested with various isotherm models (Langmuir, Freundlich, Sips, Tòth, and Redlich-Peterson isotherms) to establish the adsorption mechanisms. The testing of Langmuir and Freundlich isotherms is essential, since it reveals whether the adsorbent surface has a specific number of active sites which come in contact with adsorbates to form a permanent attachment. The test of the Langmuir isotherm ascertains physical adsorption, whereas the test of the Freundlich isotherm determines chemical adsorption, and they also facilitate the determination of adsorption mechanisms. SBA-15 and SBA-15/PA had interesting adsorption capacities and comparable adsorption capacities with respect to other adsorbents; therefore, these adsorbents are suitable for practical use. 


\section{Conclusions}

SBA-15 was modified using polyaniline on the pore wall according to textural and chemical characterization. Novel adsorbents were synthesized to effectively remove phenol pollutants from aqueous solutions. SBA-15 and SBA-15/PA mesoporous composites were synthesized by successfully modifying polyaniline on the pore wall of SBA-15 silica. The experimental results demonstrate that these composite materials are very promising candidates for the removal of phenol.

The experimental results demonstrated that SBA-15/PA is a promising candidate for the removal of phenol with an adsorption capacity of $138 \mathrm{mg} \mathrm{g}^{-1}$ compared with $85.54 \mathrm{mg} \mathrm{g}^{-1}$ for SBA-15. The surface area of SBA-15 was $654.5 \mathrm{~m}^{2} \mathrm{~g}^{-1}$, and when it was modified this decreased to $254.6 \mathrm{~m}^{2} \mathrm{~g}^{-1}$; the micropore volume, mesopore volume, total volume, and pore diameter presented the same behavior due to the fact that large amounts of polyaniline macromolecules were fixed on the walls of the pores of SBA-15. Increasing behavior of the immersion enthalpy for SBA-15 and SBA-15/PA in benzene was observed with respect to the increase of BET surface area, explained by its same porous nature. According to the enthalpies in water and benzene, the surfaces of the silicas were considered hydrophilic. There was an increase in the enthalpy when the acidity increased. The adsorbed amount and immersion enthalpy were affected in such a way that, as the content of acid groups decreased, the adsorbed amount of the phenolic compound increased.

Author Contributions: Conceptualization, L.G. and L.J.C.; methodology and formal analysis, L.J.C., L.G. and J.C.M.-P.; investigation and writing-original draft preparation, L.G. and L.J.C.; writingreview and editing, L.J.C., L.G. and J.C.M.-P. All authors have read and agreed to the published version of the manuscript.

Funding: This research received no external funding.

Institutional Review Board Statement: Not Applicable.

Informed Consent Statement: It does not apply to this research.

Data Availability Statement: We do not report any data.

Acknowledgments: The authors thank the framework agreement between Universidad Nacional de Colombia and Universidad de los Andes (Bogotá, Colombia) under which this work was carried out. Juan Carlos Moreno-Piraján thanks for an award the Facultad de Ciencias of Universidad de los Andes, number INV-2021-128-2257, and the support of "Publica tus Nuevos Conocimientos y Expón tu Nuevas Creaciones", de la Vicerrectoría de investigaciones de la Universidad de los Andes (Bogotá, Colombia).

Conflicts of Interest: The authors declare that they have no known competing financial interests or personal relationships that could appear to have influenced the work reported in this paper.

\section{References}

1. Biglari, H.; Afsharnia, M.; Alipour, V.; Khosravi, R.; Sharafi, K.; Mahvi, Y. A review and investigation of the effect of nanophotocatalytic ozonation process for phenolic compound removal from real effluent of pulp and paper industry. Environ. Sci. Pollut. Res. 2017, 24, 4105-4116. [CrossRef] [PubMed]

2. Dąbrowski, A.; Podkościelny, P.; Hubicki, Z.; Barczak, M. Adsorption of phenolic compounds by activated carbon-A critical review. Chemosphere 2005, 58, 1049-1070. [CrossRef] [PubMed]

3. Kuśmierek, K.; Świątkowski, A.; Skrzypczyńska, K.; Błażewicz, S.; Hryniewicz, J. The effects of the thermal treatment of activated carbon on the phenols adsorption. Korean J. Chem. Eng. 2017, 34, 1081-1090. [CrossRef]

4. Lorenc-Grabowska, E. Effect of micropore size distribution on phenol adsorption on steam activated carbons. Adsorption 2016, 22, 599-607. [CrossRef]

5. Rincón-Silva, N.G.; Moreno-Piraján, J.C.; Giraldo, L. Equilibrium, kinetics and thermodynamics study of phenols adsorption onto activated carbon obtained from lignocellulosic material (Eucalyptus Globulus labill seed). Adsorption 2016, 22, 33-48. [CrossRef]

6. Vargas, D.P.; Giraldo, L.; Moreno-Piraján, J.C. Effect of textural and chemical characteristics of activated carbons on phenol adsorption in aqueous solutions. Pol. J. Chem. Technol. 2017, 19, 87-93. [CrossRef]

7. Zhang, D.; Huo, P.; Liu, W. Behavior of phenol adsorption on thermal modified activated carbon. Chin. J. Chem. Eng. 2016, 24, 446-452. [CrossRef] 
8. Carvajal-Bernal, A.M.; Gómez-Granados, F.; Giraldo, L.; Moreno-Pirajan, J.C. Application of the Sips model to the calculation of maximum adsorption capacity and immersion enthalpy of phenol aqueous solutions on activated carbons. Eur. J. Chem. 2017, 8, 112-118. [CrossRef]

9. Gaber, D.; Haija, M.A.; Eskhan, A.; Banat, F. Graphene as an Efficient and Reusable Adsorbent Compared to Activated Carbons for the Removal of Phenol from Aqueous Solutions. Water Air Soil Pollut. 2017, 228, 320. [CrossRef]

10. Kowalczyk, P.; Deditius, A.; Ela, W.P.; Wiśniewski, M.; Gauden, P.A.; Terzyk, A.P.; Neimark, A.V. Super-sieving effect in phenol adsorption from aqueous solutions on nanoporous carbon beads. Carbon 2018, 135, 12-20. [CrossRef]

11. Cheng, W.; Gao, W.; Cui, X.; Ma, J.; Li, R. Phenol adsorption equilibrium and kinetics on zeolite X/activated carbon composite. J. Taiwan Inst. Chem. Eng. 2016, 62, 192-198. [CrossRef]

12. Toufaily, J.; Koubaissy, B.; Kafrouny, L.; Hamad, H.; Magnoux, P.; Ghannam, L.; Karout, A.; Hazimeh, H.; Nemra, G.; Hamieh, M.; et al. Functionalization of SBA-15 materials for the adsorption of phenols from aqueous solution. Cent. Eur. J. Eng. 2013, 3, 126-134. [CrossRef]

13. Nakagawa, K.; Namba, A.; Ariayadejwanich, P.; Tanthapanichakoon, W. Adsorption of phenol and reactive dye from aqueous solution on activated carbons derived from solid wastes. Water Res. 2004, 38, 1791-1798. [CrossRef]

14. Papadimas, S.P.; Sorial, G.A.; Suidan, M.T.; Speth, T.F. The effect of molecular oxygen on the activated carbon adsorption of natural organic matter in Ohio river water. Water Res. 1995, 29, 551-562.

15. Su, F.; Lv, L.; Hui, T.M.; Zhao, X.S. Phenol adsorption on zeolite-templated carbons with different structural and surface properties. Carbon 2005, 43, 1156-1164. [CrossRef]

16. Pan, B.C.; Zhang, X.; Zhang, W.M.; Zhang, Q.X. Adsorption of phenolic compounds from aqueous solution onto a macroporous polymer and its aminated derivative: Isotherm analysis. J. Hazard. Mater. 2005, 121, 233-241. [CrossRef] [PubMed]

17. Zhao, Z.G.; Zhang, L.H.; Lin, Y. Thermodynamics of Adsorption of Organic Compounds at the Silica Gel/Nonpolar Solvent Interfaces. J. Colloid Interface Sci. 1994, 166, 23-28. [CrossRef]

18. Parida, S.; Dash, S.; Patel, S.; Mishra, B. Adsorption of organic molecules on silica surface. Adv. Colloid Interface Sci. 2006, 121,77-110. [CrossRef]

19. Zhang, W.; Chen, J.; Pan, B.; Zhang, Q. Modeling cooperative adsorption of aromatic compounds in aqueous solutions to nonpolar adsorbent. Sep. Purif. Technol. 2006, 49, 130-135. [CrossRef]

20. Delval, F.; Crini, G.; Vebrel, J. Removal of organic pollutants from aqueous solutions by adsorbents prepared from an agroalimentary by-product. Bioresour. Technol. 2006, 97, 2173-2181. [CrossRef]

21. Wang, S.; Boyjoo, Y.; Choueib, A.; Zhu, Z.H. Removal of dyes from aqueous solution using fly ash and red mud. Water Res. 2005, 39, 129-138. [CrossRef]

22. Alkaram, U.F.; Mukhlis, A.A.; Al-Dujaili, A.H. The removal of phenol from aqueous solutions by adsorption using surfactantmodified bentonite and kaolinite. J. Hazard. Mater. 2005, 169, 324-332. [CrossRef]

23. Koubaissy, B.; Toufaily, J.; Kafrouny, L.; Joly, G. Industrial water treatment, by adsorption, using organized mesoporous materials. Phys. Procedia 2011, 21, 228-233. [CrossRef]

24. Khalid, M.; Joly, G.; Renaud, A.; Magnoux, P. Removal of Phenol from Water by Adsorption Using Zeolites. Ind. Eng. Chem. Res. 2004, 43, 5275-5280. [CrossRef]

25. Koubaissy, B.; Joly, G.; Magnoux, P. Adsorption and Competitive Adsorption on Zeolites of Nitrophenol Compounds Present in Wastewater. Ind. Eng. Chem. Res. 2008, 47, 9558-9565. [CrossRef]

26. Koubaissy, B.; Joly, G.; Batonneau-Gene, I.; Magnoux, P. Adsorptive Removal of Aromatic Compounds Present in Wastewsssgater by Using Dealuminated Faujasite Zeolite. Ind. Eng. Chem. Res. 2011, 50, 5705-5713. [CrossRef]

27. Koubaissy, B.; Toufaily, J.; El-Murr, M.; Daou, T.J.; Joly, G.; Magnoux, P.; Hamieh, T. Adsorption Kinetics and Equilibrium of Phenol Drifts on three Zeolites. Cent. Eur. J. Eng. 2012, 2, 435-444. [CrossRef]

28. Zhao, D.Y.; Feng, J.; Huo, Q.; Melosh, N. Triblock copolymer syntheses of mesoporous silica with periodic 50 to 300 angstrom pores. Science 1998, 279, 548-552. [CrossRef]

29. Zhao, D.Y.; Huo, Q.; Feng, J.; Chmelka, B.F. Nonionic Triblock and Star Diblock Copolymer and Oligomeric Surfactant Syntheses of Highly Ordered, Hydrothermally Stable Mesoporous Silica Structures. J. Am. Chem. Soc. 1998, 120, 6024-6036, Erratum in J. Am. Chem. Soc. 2014, 136, 10546. [CrossRef]

30. Zhang, L.X.; Yu, C.C.; Zhao, W.R.; Hua, Z.L. Preparation of multi-amine-grafted mesoporous silicas and their application to heavy metal ions adsorption. J. Non-Cryst. Solids 2007, 353, 4055-4061. [CrossRef]

31. Brunel, D. Functionalized micelle-templated silicas (MTS) and their use as catalysts for fine chemicals. Microporous Mesoporous Mater. 1999, 27, 329-344. [CrossRef]

32. Stein, A.; Melde, B.J.; Schroden, R.C. Hybrid Inorganic-Organic Mesoporous Silicates-Nanoscopic Reactors Coming of Age. Adv Mater. 2000, 12, 1403-1419. [CrossRef]

33. Mangrulkar, P.A.; Kamble, S.P.; Meshramb, J.; Rayalu, S.S. Adsorption of phenol and o-chlorophenol by mesoporous MCM-41. J. Hazard. Mater. 2008, 160, 414-421. [CrossRef] [PubMed]

34. Zhai, Q.; Li, X. Efficient removal of cadmium (II) with SBA-15 nanoporous silica: Studies on equilibrium, isotherm, kinetics and thermodynamics. Appl. Water Sci. 2019, 9, 143. [CrossRef]

35. Kjellman, T.; Reichhardt, N.; Sakeye, M.; Smått, J.H.; Lindén, M.; Alfredsson, V. Independent Fine-Tuning of the Intrawall Porosity and Primary Mesoporosity of SBA-15. Chem. Mater. 2013, 25, 1989-1997. [CrossRef] 
36. Weng, S.; Lin, Z.; Zhan, Y.; Chen, L.; Zhou, J. Facile synthesis of SBA-15/polyaniline nanocomposites with high electrochemical activity under neutral and acidic conditions. React. Funct. Polym. 2009, 69, 130-136. [CrossRef]

37. Filip, A.; Macdonald, T.; Martis, V.; Parkin, I. Evaluation of the BET theory for the characterization of meso and microporous MOFs. Small Methods 2018, 2, 11.

38. Boehm, H. Chemical Identification of Surface Groups. Adv. Catal. 1966, 16, 179-274.

39. Babić, B.; Milonjić, S.; Polovina, M.; Kaludierović, B. Point of zero charge and intrinsic equilibrium constants of activated carbon cloth. Carbon 1999, 37, 477-481. [CrossRef]

40. Moreno, J.; Giraldo, L. Determination of the immersion enthalpy of activated carbon by microcalorimetry of the heat conduction Instrum. Sci. Technol. 2000, 28, 171-178. [CrossRef]

41. Thommes, M.; Kaneko, K.; Neimark, A.V.; Olivier, J.P.; Rodriguez-Reinoso, F.; Rouquerol, J.; Sing, K.S. Physisorption of gases, with special reference to the evaluation of surface area and pore size distribution (IUPAC Technical Report). Pure Appl. Chem. 2015, 87, 1117. [CrossRef]

42. Takamori, D.; Bizeto, M.; Fantini, A.; Rubinger, C.; Faez, R.; Martins, T. Polyaniline inclusion into ordered mesoporous silica matrices: Synthesis, characterization and electrical transport mechanism. Microporous Mesoporous Mater. 2019, 274, $212-219$. [CrossRef]

43. Boukoussa, B.; Hakiki, A.; Nunes-Beltrao, A.; Hamacha, R.; Azzouz, A. Assessment of the intrinsic interactions of nanocomposite polyaniline/SBA-15 with carbon dioxide: Correlation between the hydrophilic character and surface basicity. J. CO2 Util. 2018, 26, 171-178. [CrossRef]

44. Santos, S.; Cecilia, J.; Vilarrasa-García, E.; Silva Junior, I.; Rodríguez-Castellón, E.; Azevedo, D. The effect of structure modifying agents in the SBA-15 for their application in the biomolecules adsorption. Microporous Mesoporous Mater. 2016, 232, 53-64. [CrossRef]

45. Rodríguez-Estupiñán, P.; Giraldo, L.; Moreno-Piraján, J.C. Calorimetric study of amino-functionalised SBA-15. J. Therm. Anal. Calorim. 2015, 121, 127-134. [CrossRef]

46. Navarrete, L.; Giraldo, L.; Moreno, J.C. Influence of surface chemistry on the immersion enthalpy of activated carbons in aqueous solutions of phenol and 4-nitro phenol. Rev. Colomb. Chem. 2006, 35, $215-224$.

47. Rodríguez-Estupiñán, F.; Giraldo, L.; Moreno-Piraján, J.C. Relationship between immersion enthalpies of activated carbons modified in their surface chemistry in different liquids and their physicochemical characteristics. Afinidad Rev. Quím. Teór. Apl. 2015, 72, 114-119.

48. Vargas, D.; Giraldo, L.; Moreno-Piraján, J.C. Characterization of granular activated carbon prepared by activation with CaCl ${ }_{2}$ by means of gas adsorption and immersion calorimetry. Adsorption 2016, 22, 717-723. [CrossRef]

49. Carvajal-Bernal, A.; Gómez-Granados, F.; Giraldo, L.; Moreno-Piraján, J.C. A study of the interactions of activated carbon-phenol in aqueous solution using the determination of immersion enthalpy. Appl. Sci. 2018, 8, 843. [CrossRef]

50. Asmaly, H.; Ihsanullah; Abussaud, B.; Saleh, T.; Laoui, T.; Gupta, K.; Ali, M. Adsorption of phenol on aluminum oxide impregnated fly ash. Desalin. Water Treat. 2016, 57, 6801-6808. [CrossRef]

51. Li, Q.; Yu, H.; Song, J.; Pan, X.; Liu, J.; Wang, Y.; Tang, L. Synthesis of SBA-15/polyaniline mesoporous composite for removal of resorcinol from aqueous solution. Appl. Surf. Sci. 2014, 290, 260-266. [CrossRef]

52. Kundu, S.; Gupta, A.K. Arsenic adsorption onto iron oxide-coated cement (IOCC): Regression analysis of equilibrium data with several isotherm models and their optimization. Chem. Eng. J. 2006, 122, 93-106. [CrossRef]

53. Freundlich, H.M.F. Over the adsorption in solution. J. Phys. Chem. 1906, 57, 385-471.

54. Adamson, A.W.; Gast, A.P. Physical Chemistry of Surfaces, 6th ed.; Wiley Interscience: New York, NY, USA, 1997.

55. Hamdaoui, O.; Naffrechoux, E. Modeling of adsorption isotherms of phenol and chlorophenols onto granular activated carbon. Part II. Models with more than two parameters. J. Hazard. Mater. 2007, 147, 401-411. [CrossRef] [PubMed]

56. Ho, Y.S.; Porter, J.F.; Mckay, G. Equilibrium isotherm studies for the sorption of divalent metal ions onto peat: Copper, nickel and lead single component systems. Water Air Soil Pollut. 2002, 141, 1-33. [CrossRef]

57. Prasad, R.K.; Srivastava, S.N. Sorption of distillery spent wash onto fly ash: Kinetics and mass transfer studies. Chem. Eng. J. 2009, 146, 90-97.

58. Gimbert, F.; Morin-Crini, N.; Renault, F.; Badot, P.M.; Crini, G. Adsorption isotherm models for dye removal by cationized starch-based material in a single component system: Error analysis. J. Hazard. Mater. 2008, 157, 34-46. [CrossRef] 